\title{
Radiological Findings of Pulmonary Tuberculosis in Children at Dr. Hasan Sadikin General Hospital Bandung 2018-2019
}

\author{
Nanda Mia Ghaesani, ${ }^{1}$ Ristaniah Rose Effendy, ${ }^{2}$ Diah Asri Wulandari ${ }^{3}$ \\ ${ }^{1}$ Faculty of Medicine Universitas Padjadjaran, Indonesia, ${ }^{2}$ Department of Radiology, Faculty of \\ Medicine Universitas Padjadjaran/Dr. Hasan Sadikin General Hospital, Bandung, Indonesia, \\ ${ }^{3}$ Department of Child Health, Faculty of Medicine Universitas Padjadjaran/Dr. Hasan Sadikin \\ General Hospital, Bandung, Indonesia
}

\section{Abstract}

Background: Tuberculosis (TB) remains a major cause of death worldwide, especially in children. Indonesia is ranked second as the largest contributor to TB. Chest X-rays have been used to diagnose pulmonary TB in children, however, the results are varied. Therefore, this study was performed to explore the radiological findings among children with pulmonary TB.

Methods: Retrospective descriptive study was conducted by analyzing the chest X-ray findings retrieved from the medical records of all pulmonary TB children treated at Dr. Hasan Sadikin General Hospital during 2018 to 2019. Inclusion criteria were medical records of patients aged 1 month to 18 years diagnosed with pulmonary TB who underwent chest X-ray ( $\mathrm{n}=223)$.

Results: The highest incidence of pulmonary TB was found in the group of 10-18 years (43.9\%) and female $(50.2 \%)$. The results of chest X-ray were infiltrates $(65.0 \%)$, lymphadenopathy $(11.7 \%)$, cavity (7.6\%), calcifications (7.6\%), miliary (4.9\%), pleural effusion (3.1\%) and atelectasis $(1.8 \%)$.

Conclusion: Infiltrates are the major finding on Chest X-ray in children with TB.

Keywords: Chest X-ray, children, pulmonary tuberculosis

\section{Introduction}

Tuberculosis (TB) remains a major cause of death worldwide according to the World Health Organization (WHO). ${ }^{1}$ Indonesia is ranked as the second largest TB contributor with 845,000 cases in 2019 , WHO reports that there are approximately $119,520(12 \%)$ cases of TB in children all over the world, and about 14,520 (16\%) children died of TB in 2019. ${ }^{1}$ High mortality rates for children compared to their estimated of cases suggests poorer access to diagnosis and treatment. ${ }^{1}$ Approximately 73,285 cases of pulmonary TB in West Java with 31,814 cases in children aged 1 month to less than 18 years. Bandung, is one of the cities in West Java that has the highest incidence of pulmonary TB with an estimated 5,592 cases in 2018 according to Basic Health Research
(Riset Kesehatan Dasar, Riskesdas), ${ }^{2}$ the mortality rate of TB is almost $50 \%$ in children aged less than 5 years. ${ }^{3}$

Pulmonary tuberculosis is an infectious disease caused by Mycobacterium tuberculosis (MTB), ${ }^{4}$ mostly transmitted by inhalation of droplets nuclei when a person with active pulmonary TB coughs, sneezes, or talks. Those who have a poor immune system, and live in TB endemic areas, poor socioeconomic conditions, and smoking may have an increased incidence number of TB. Children are prone to have a high risk of getting TB. Clinical manifestations are mostly general and non-specific symptoms similar to other conditions. Children with pulmonary TB generally show no symptoms for some time due to a typical paucibacillary disease. $^{4}$

Diagnosis of pulmonary TB is complicated

Correspondence: Nanda Mia Ghaesani, Faculty of Medicine Universitas Padjadjaran, Jalan Raya Bandung - Sumedang Km. 21 Jatinangor, Sumedang, Indonesia, E-mail: nandamia66@gmail.com 
in children, because it is difficult to isolate MTB from sputum. Therefore chest X-ray remains a supporting tool for the diagnosis of TB in children. ${ }^{5}$ There are several radiological findings of pediatric pulmonary TB such as lymphadenopathy, infiltrates, calcifications, pleural effusions, and others. Hilar lymphadenopathy is a characteristic feature of TB in children and is often the only radiological finding in $50 \%$ of pediatric cases. ${ }^{6}$ Chest X-ray in most cases of lung caused by chronic infection or inhalation of foreign bodies can sometimes resemble pulmonary TB. ${ }^{7}$ A normal chest X-ray of children can often resemble an abnormal chest X-ray because of less than optimal chest X-ray taking and misinterpretation. ${ }^{6}$ Therefore, understanding chest X-ray of pediatric pulmonary TB for diagnostic purposes in both clinical practice and research is important.

Previous study has shown that chest $\mathrm{X}$-ray findings is mostly infiltrate $(55.2 \%)$, and other findings in small proportion such as pleural effusion with infiltrate, milliary, pleural effusion, and atelectasis. ${ }^{8}$ Another study has found different findings mostly as hilar lymphadenopathy (52\%) and a small proportion as calcification, miliary. ${ }^{9}$ This abnormal chest X-ray findings have been found in patients with negative tuberculin skin test (TST) results. Since there has been no similar study conducted in Bandung, this study aimed to explore radiological findings among children with pulmonary TB treated at Dr. Hasan Sadikin General Hospital, Bandung.

\section{Methods}

A retrospective descriptive study was conducted by looking at the chest X-ray findings from the medical records of pediatric patients diagnosed with pulmonary TB. This study was conducted at the pediatric ward of Dr. Hasan Sadikin General Hospital Bandung in 20182019. A total sampling method was employed $(\mathrm{n}=713)$. The inclusion criteria for this study were medical records of patients aged 1 month to 18 years diagnosed with pulmonary TB who underwent chest X-ray. Children with extrapulmonary TB $(n=357)$ were excluded. Furthermore, incomplete medical records were also excluded $(n=133)$. This research has been approved by the Research Ethics Committee, Universitas Padjadjaran with number 813/ UN6.KEP/EC/2020 and also by the Research Development and Ethics Committee of Dr. Hasan Sadikin General Hospital with number LB.02.01/X.2.2.1/23478/2020.
In children, TB was diagnosed based on the typical clinical symptoms of tuberculosis, with one or more of the following: (a) weight loss or no gain in the previous 2 months; (b) fever ( $\geq 2$ weeks) and /or recurrent without apparent cause; (c) cough ( $\geq 2$ weeks); (d) lethargic ( $\geq 2$ weeks). These symptoms persisted despite adequate therapy, positive bacteriological confirmation by positive microbiological examination (acid-fast bacilli or rapid molecular test), evidence of TB infection (Positive tuberculin test results or close contact with TB patients), and suggestive TB chest X-ray images. ${ }^{10}$

The following information was extracted from available medical records such as age, gender, TB treatment history, contact with adults with pulmonary TB, Bacillus Calmette Guerin (BCG) immunization, nutritional status, other clinical findings or complaints felt by the patient observed by the examiner at the time of the examination, such as weight loss or no increasing weight in the previous 2 months, fever ( $\geq 2$ weeks), cough ( $\geq 2$ weeks), lethargy ( $\geq 2$ weeks), enlarged lymph nodes $\geq 1 \mathrm{~cm}$ in size, ${ }^{10}$ positive TST, $^{11}$ bacteriological confirmation, and comorbidity.

Chest X-ray was reviewed for the presence of the following variables such as hilar/ paratracheal lymphadenopathy, described as nodular masses or lobulated opaque according to site. ${ }^{12}$ Furthermore, infiltrate was described as a cloudy or infiltrating spot which is generally over the upper plane of the lung although it can occur anywhere in the lung. ${ }^{6}$ Milliary was described as small nodular opacities $(\leq 3 \mathrm{~mm}$ in diameter), diffuse, and uniform across the plane of the lung to the edge of the lung plane, ${ }^{6}$ whereas cavity was described as air-filled cavity occuring in areas with parenchymal damage. ${ }^{6}$ Calcification was described as hard or calcified node, atelectasis was described as collapse of the air space, and pleural effusion was described as homogeneously opacified fluid level or pleural opacification..$^{12,13}$ The data were processed using Microsoft Excel 2016, and presented descriptively by calculating the amount and proportion in the tables.

\section{Results}

A total of 223 medical records at Dr. Hasan Sadikin General Hospital were included in this study taken from January 2018 to December 2019. The mean age of the patients was 7.81 years and the median age was 8 years (Range $<1-18$ years old). Most of the patients were aged between $10-18$ years $(43.9 \%)$ with the 
Table 1 Characteristics of Children with Pulmonary Tuberculosis at Dr. Hasan Sadikin General Hospital Bandung Year 2018-2019 $(n=223)$

\begin{tabular}{|c|c|}
\hline Characteristic & n (\%) \\
\hline \multicolumn{2}{|l|}{ Age, years old } \\
\hline Mean & 7.81 \\
\hline Median (range) & $8(<1-18)$ \\
\hline \multicolumn{2}{|l|}{ Age group in years } \\
\hline$<1$ & $24(10.8)$ \\
\hline $1-<5$ & $73(32.7)$ \\
\hline $5-<10$ & $28(12.6)$ \\
\hline $10-18$ & $98(43.9)$ \\
\hline \multicolumn{2}{|l|}{ Gender } \\
\hline Male & $111(49.8)$ \\
\hline Female & $112(50.2)$ \\
\hline TB treatment history* & $110(49.3)$ \\
\hline History of TB contact & $62(27.8)$ \\
\hline BCG immunization** & $151(67.7)$ \\
\hline \multicolumn{2}{|l|}{ Nutritional status } \\
\hline Severe malnutrition & $84(37.7)$ \\
\hline Moderate malnutrition & $52(23.3)$ \\
\hline Normal & $84(37.7)$ \\
\hline Overweight & $3(1.3)$ \\
\hline \multicolumn{2}{|l|}{ Clinical findings } \\
\hline Fever $\geq 2$ weeks & $109(48.9)$ \\
\hline Cough $\geq 2$ weeks & $104(46.6)$ \\
\hline Weight loss or no gain in the previous 2 months & $72(32.3)$ \\
\hline Malaise & $19(8.5)$ \\
\hline Lymph node enlargement & $29(13.0)$ \\
\hline Positive TST*** & $35(15.7)$ \\
\hline \multicolumn{2}{|l|}{ Bacteriological confirmation } \\
\hline Positive $\mathrm{AFB}^{* * * *}$ & $22(9.9)$ \\
\hline Positive GeneXpert & 27 (12.1) \\
\hline Positive culture & $1(0.4)$ \\
\hline \multicolumn{2}{|l|}{ Comorbids } \\
\hline Autoimmune disease & $9(4.0)$ \\
\hline Cancer & $4(1.8)$ \\
\hline Chronic lung disease & $11(4.9)$ \\
\hline Diabetes mellitus & $1(0.5)$ \\
\hline Malnutrition & $136(61.0)$ \\
\hline Nephrotic Syndrome & $8(3.6)$ \\
\hline Pneumonia & $56(25.1)$ \\
\hline HIV & $6(2.7)$ \\
\hline
\end{tabular}


Table 2 Distribution of Chest X-ray Findings of Pulmonary Tuberculosis in Children at Dr. Hasan Sadikin General Hospital Bandung Year 2018-2019

\begin{tabular}{lcc}
\hline \multicolumn{1}{c}{ Pulmonary TB (n= 223) } & $\mathbf{n}$ & $\mathbf{\%}$ \\
\hline Infiltrate & 145 & 65.0 \\
Lymphadenopathy (hilar/paratracheal) & 26 & 11.7 \\
Cavity & 17 & 7.6 \\
Calcification & 17 & 7.6 \\
Milliary & 11 & 4.9 \\
Pleural effusion & 7 & 3.1 \\
Atelectasis & 4 & 1.8 \\
\hline
\end{tabular}

Note: One pediatric pulmonary TB patient can show more than 1 radiological findings

proportion of male patients (49.8\%) less than female and most of them came with a history of TB treatment $(49.3 \%)$. History of contact with the source of TB cases was found in $27.8 \%$ of patients. Most of the subjects had a history of BCG immunization $(67.7 \%)$ and the nutritional status was mostly undernutrition which was severe $(37.7 \%)$ and moderate malnutrition $(23.3 \%)$. Fever $\geq 2$ weeks was the most common clinical findings (48.9\%) and $15.7 \%$ had a positive TST. Bacteriological confirmation showed positive AFB in only $9.9 \%$ of patients, positive GeneXpert (12.1\%), and positive culture $(0.4 \%)$. Most of the patients had more than one disease that occured simultaneously with malnutrition $(61.0 \%)$.

The most frequent lesions found on chest X-ray of pediatric pulmonary TB cases were infiltrates $(65.0 \%)$, followed by lymphadenopathy $(11.7 \%)$, cavities $(7.6 \%)$, calcifications $(7.6 \%)$, milliary $(4.9 \%)$, pleural effusion $(3.1 \%)$ and atelectasis $(1.8 \%)$ as shown in Table 2.

\section{Discussion}

Pediatric tuberculosis patients at Dr. Hasan Sadikin General Hospital Bandung in 20182019 were mostly aged between $10-18$ years $(69.4 \%)$ and the least was younger than 1 -year-old (10.8\%). This is similar to a study in Shandong, China ${ }^{14}$ in 2019, reporting that the incidence of pulmonary TB often occurred in the 15-17 year age group (83.3\%). This finding is also in line with studies showing that adolescents have a higher risk of developing TB disease because most of adolescents have high levels of TB exposure and they are more likely to spend time in an enclosed space, such as social gathering places or schools. ${ }^{6,11}$ Furthermore, most of pulmonary TB in children is female (50.2\%), similar to the previous study which accounted for $56.6 \%{ }^{15}$

Contact with the source of TB cases was found in $27.8 \%$ of patients, slightly higher than the previous study. ${ }^{14}$ This difference might be caused by the nature of the disease. BCG protection against pulmonary TB is well known with efficacy rates $(0-80 \%)$ and is greater when BCG is given in infancy or at school age. ${ }^{16}$ However in this study pulmonary TB is mostly observed in $67.7 \%$ of children who have a history of BCG immunization. Moreover, a research conducted in Mumbai, India ${ }^{15}$ has shown that almost all children have been vaccinated with $B C G$, suggesting that $T B$ can occur in children vaccinated with BCG .

Most of the nutritional status in this study is undernutrition, which is severe $(37.7 \%)$ and moderate malnutrition $(23.3 \%)$. This finding is in line with a study in North Sumatera, Indonesia. ${ }^{17}$ Undernutritional status has a 3.31 times greater risk of experiencing pulmonary TB in children compared to children who have good nutritional status. The most common clinical finding in this study is fever at $\geq 2$ weeks $(48.9 \%)$ similar to the previous study. ${ }^{10,18}$

Tuberculin skin test (TST) shows positive result in $15.7 \%$ of patients. However, a negative result may be pointing out falsenegative TST results due to incorrect test administration or interpretation, immune disorders, malnutrition, immunosuppressive medications, neonatal patient, severe TB cases, malignancy, and expired TST kit. A negative TST does not rule out MTB infection or the possibility of TB. Therefore, it is important to carry out other TB diagnostic tests. ${ }^{11}$

Acid-fast bacilli and GeneXpert examination in this study have more negative results. This finding is similar to another study which showed more negative results of AFB and GeneXpert examination. ${ }^{18}$ The negative AFB examination and GeneXpert results might be due to TB in young children who generally have paucibacillary disease, accompanied by inadequate cough physiology to expectorate infectious sputum. ${ }^{4}$ Culture examinations 
were mostly done with blood specimen that were not included in this study. Most of the results from sputum or gastric aspirates were negative $(8.5 \%)$. The percentage of patients with culture negative in England is 13\%. ${ }^{19}$ This negative result due to negative cultures could include multiple disease states. ${ }^{19}$ Several medical conditions are comorbid for TB. The most comorbidity in this study is malnutrition (59.6\%). Malnutrition can lead to secondary immunodeficiency that increases the host's susceptibility to infection.

The most common chest X-ray finding is infiltrate $(65.0 \%)$, similar to another study. ${ }^{8}$ The infiltrates in this study can be caused by MTB that reaches the pulmonary alveoli which then causes parenchymal inflammation. Another finding is lymphadenopathy $(11.7 \%) .^{5}$ Hilar lymphadenopathy is the hallmark of TB in children and is often the only chest X-ray finding. ${ }^{6}$ Lymphadenopathy is more common in younger children than adolescents. It may also be due to parenchymal lesions such as infiltrates that may obstruct the visualization of enlarged lymph nodes, although both findings may appear at the same time. ${ }^{5}$ Therefore, it is important not to rule out pulmonary TB despite the absence of the most characteristic radiological findings which is lymphadenopathy and it is still necessary to combine radiological examination with other diagnostic tests. Cavity in this study has mostly been observed in the 10-18 year age group $(7.6 \%)$, which is more common than the study in Mumbai, India. ${ }^{15}$ Cavitation in older children and adolescents is higher than in younger children. ${ }^{6}$ Cavitation can occur in older children due to higher mycobacterial load which is similar to the adult-type disease. ${ }^{15}$ Some lesions in lung tissue can mostly heal to form fibrosis or calcification. Calcification can occur from 6 months to 4 years after infection, however, it may occur earlier in young children. Miliary lesion results from MTB infiltration into the blood vessels, leading to hematogenous dissemination. ${ }^{13}$ This type of lesion can occur in young children because of their immature immune system. ${ }^{20}$

Pleural effusion with bacteriological confirmation has been found in only a small percentage which is similar to the study in Mozambique. ${ }^{5}$ This is mostly due to a delayed-type hypersensitivity reaction to MTB antigens that leak into the pleural space from the subpleural primary focus. ${ }^{13}$ Furthermore, atelectasis may occur because the thymus gland can resemble to atelectasis, especially on chest X-ray with rotational asymmetry or caused by bronchial obstruction. ${ }^{6}$

The limitation of this study is the use of a retrospective study. There is a lot of data missing or not available. Descriptive data might not determine a clear association between variable data and radiological findings. Most of the population was drawn from patients being treated with severe TB or pulmonary TB with other diseases that could provide a bias. Most patients had only an anteroposterior (AP) projection and lacked of the lateral projection, which is important for lymphadenopathy evaluation, thus, some findings might have been missed. Further research is needed to determine the radiological findings of pulmonary TB in children with better research methods including patients who were treated at outpatient clinic as the population.

This study concludes that most of the chest X-ray findings of pediatric pulmonary TB patients treated at Dr. Hasan Sadikin General Hospital Bandung has an infiltrate, followed by lymphadenopathy, cavity, calcification, milliary, pleural effusion and atelectasis. These findings need further research to explore the use of chest X-ray as diagnostic criteria for TB in children.

\section{References}

1. World Health Organization. Global tuberculosis report 2020. Geneva: WHO; 2020.

2. Tim Riskesdas 2018 Kementerian Kesehatan RI. Laporan Provinsi Jawa Barat: Riskesdas 2018. Jakarta: Lembaga Penerbit Badan Penelitian dan Pengembangan Kesehatan; 2019.

3. Roy RB, Whittaker E, Seddon JA, Kampmann B. Children and mycobacterium tuberculosis: a review of susceptibility and protection. Lancet Infect Dis. 2019; 19(3):e-96-108.

4. Holmberg PJ, Temesgen Z, Banerjee R. Tuberculosis in children. Pediatr Rev. 2019;40(4):168-78.

5. García-basteiro AL, López-varela E, Augusto OJ, Gondo K, Muñoz J, Sacarlal J, et al. Radiological findings in young children investigated for tuberculosis in Mozambique. PLoS One. 2015;10(5):e0127323.

6. Smith KC, John SD. Pediatric TB radiology for clinicians. San Antonio, TX: Heartland National TB Center; 2012.

7. Majdawati A. Uji diagnostic gambaran lesi foto thorax pada penderita dengan klinis tuberkulosis paru. Mutiara Medika. 
2010;10(2):180-8.

8. Salwani D, Nasir UZ, Yunihastuti E, Harimurti K, Andriansjah A. Kemampuan gabungan gejala klinis dan pemeriksaan radiologis serta biakan MGIT 960 dalam diagnosis tuberkulosis paru pada pasien HIV. J Penyakit Dalam Indones. 2018;5(2):88-93.

9. Poluan AGA, Loho E, Ali RH. Hubungan gambaran fototoraks dan uji tuberkulin pada anak dengan diagnosis tuberkulosis paru di RSUP Prof. DR. R. D. Kandou Manado periode Januari 2012-Desember 2012. e-Clinic. 2014;2(1):3664.

10. Asik A, Hastuti EB, Evarini, editors. Petunjuk teknis manajemen dan tatalaksana TB anak. Jakarta: Direktorat Jenderal Pencegahan dan Pengendalian Penyakit Kementerian Kesehatan Republik Indonesia; 2016.

11. World Health Organization. Guidance for national tuberculosis programmes on the management of tuberculosis in children. $2^{\text {nd }}$ Ed. Geneva: World Health Organization; 2014.

12. Manikkam S, Archary M, Bobat R. Chest $\mathrm{X}$-ray patterns of pulmonary multidrugresistant tuberculosis in children in a high HIV-prevalence setting. S Afr J Radiol. 2016;20(1):1-6.

13. Roya-Pabon CL, Perez-Velez CM. Tuberculosis exposure, infection and disease in children: a systematic diagnostic approach. Pneumonia (Nathan).2016;8:23.

14. Tao NN, Li YF, Liu YX, Liu JY, Song WM, Liu
Y, et al. Epidemiological characteristics of pulmonary tuberculosis among children in Shandong, China, 2005-2017. BMC Infect Dis. 2019;19(1):408.

15. Pereira NMD. Clinical profile and outcome of children with tuberculosis in a tertiary care hospital in Mumbai, India. Sri Lanka J Child Health. 2019;48(4):338-44.

16. Mangtani P, Abubakar I, Ariti C, Beynon R, Pimpin L, Fine PEM, et al. Protection by BCG vaccine against tuberculosis: a systematic review of randomized controlled trials. Clin Infect Dis. 2014;58(4):470-80.

17. Gurning FP, Eliska E, Pratama MY. Analysis of factors related to the incidence of pediatric pulmonary tuberculosis in Sibuhuan General Hospital. Jurnal Berkala Epidemiologi. 2018;6(3):268-75.

18. Soekotjo FN, Sudarwati S, Alam A. Clinical profile of TB in children at Pediatric Outpatient Clinic Hasan Sadikin Hospital Bandung 2016. J Med Health. 2019;2(3):818-27.

19. Nguyen MVH, Levy NS, Ahuja SD, Trieu L, Proops DC, Achkar JM. Factors associated with sputum culturenegative vs culture-positive diagnosis of pulmonary tuberculosis. JAMA Netw Open. 2019;2(2):e187617.

20. Concepcion NDP, Laya BF, Andronikou S, Daltro PAN, Sanchez MO, Uy JAU, et al. Standardized radiographic interpretation of thoracic tuberculosis in children. Pediatr Radiol. 2017;47(10):1237-48. 